\title{
Traumatic Events and Tonic Immobility
}

\author{
Arturo Bados ${ }^{1}$, Lidia Toribioº ${ }^{2}$ and Eugeni García-Grau ${ }^{1}$ \\ ${ }^{1}$ Universidad de Barcelona (Spain) \\ ${ }^{2}$ Consorci Sanitari de l'Anoia (Spain)
}

\begin{abstract}
Tonic immobility is a basic defense strategy which has not been studied in depth in humans. Data suggest that it may be a relatively frequent phenomenon in victims of rape and sexual abuse, but its occurrence has not been systematically explored in other types of trauma. We carried out a retrospective study in a sample of 100 university students to establish whether tonic immobility varies depending on the nature of the worst trauma experienced, defined subjectively by each participant. Immobility was assessed using the Tonic Immobility Scale and traumas were assessed using the modified Traumatic Events Questionnaire. Seventy percent of the sample had experienced trauma of some kind. There were no significant differences in tonic immobility between different types of trauma (e.g., physical abuse, assault or aggression, serious accident), except that the mean tonic immobility score was significantly higher in the group with trauma due to physical/psychological or sexual abuse than in the group with trauma due to receiving news of the mutilation, serious injury, or violent or sudden death of a loved one. We conclude tentatively that tonic immobility may be typical not only of sexual traumas, but of other kinds of directly experienced traumas as well.

Keywords: tonic immobility, trauma, Tonic Immobility Scale, Traumatic Events Questionnaire, defensive strategies
\end{abstract}

La inmovilidad tónica es una estrategia defensiva básica que ha sido muy poco estudiada en seres humanos. Hay datos de que puede ser un fenómeno relativamente frecuente en víctimas de violación y abuso sexual, pero su ocurrencia no ha sido investigada de forma sistemática en otro tipo de traumas. Así pues, estudiamos retrospectivamente en una muestra de 100 estudiantes universitarios si la inmovilidad tónica varía en función del peor trauma experimentado, definido este según la valoración subjetiva de cada participante. La inmovilidad fue evaluada mediante la Escala de Inmovilidad Tónica y los traumas mediante el Cuestionario de Eventos Traumáticos modificado. Un $70 \%$ de la muestra había experimentado algún trauma. No hubo diferencias significativas en inmovilidad tónica entre diferentes tipos de traumas (p.ej., maltrato, atraco o agresión, accidente grave), excepto que la media de inmovilidad tónica fue significativamente mayor en el grupo con trauma de maltrato físico/psicológico o abuso sexual que en el grupo con trauma subsecuente a noticias de mutilación, heridas graves o muerte violenta o inesperada de alguien cercano. Así pues, puede concluirse tentativamente que la inmovilidad tónica puede ser típica no sólo de traumas sexuales, sino también de otro tipo de traumas directamente experimentados..

Palabras clave: Inmovilidad tónica, trauma, Escala de Inmovilidad Tónica, Cuestionario de Eventos Traumáticos, estrategias defensivas.

Part of this work was presented as a poster at the V World Congress of Behavior and Cognitive Therapies held in Barcelona, July 11-14, 2007.

Correspondence concerning this article should be addressed to Arturo Bados, Departamento de Personalidad, Evaluación y Tratamiento Psicológico, Facultad de Psicología, Universidad de Barcelona, (Spain). Phone: 34-933125106. FAX: 34-934021362. E-mail: abados@ub.edu

Translation: Virginia Navascués Howard

How to cite the authors of this article: Bados, A., Toribio, L. and García-Grau, E. 
Gray (1987) described a sequence of four defensive responses that occur depending on the proximity of danger. These responses are alert or vigilant immobility (alert posture, attention aimed at locating the possible danger), escape, fighting, and tonic immobility (see also Marks, 1987/1991). The first three have been extensively studied in people and animals, whereas the last one has been much investigated in the animal world, but very little in humans.

Tonic immobility is characterized by pronounced physical and verbal immobility, trembling, muscular rigidity, sensations of cold and numbness or insensitivity to intense or painful stimulation. Tonic immobility is induced by conditions of fear and physical restriction, although it can also occur in the absence of the latter, so the important aspect may be the perceived incapacity to escape (Heidt, Marx, \& Forsyth, 2005; Moskowitz, 2004). Tonic immobility is an adaptive response when one does not perceive the possibility of escaping or of winning a fight. In effect, as predators tend to react basically to the movement of their prey, if the latter remain immobile instead of struggling or fighting, the probability of escaping increases because the predator often is distracted and temporarily releases its prey (Bracha, 2004; Marks, 1987; Moskowitz, 2004).

Suarez and Gallup (1979) emphasized that induced paralysis in some rape victims may be an example of tonic immobility in humans. Galliano, Noble, Travis, and Puechl (1993) studied tonic immobility in 35 female rape victims. Of them, $37 \%$ were classified in the category of immobility during the rape; this classification was based on having scored 6 or 7 on a 7-point scale of two questions about the degree to which they were immobile or paralyzed during the aggression and the incapacity to move even in the absence of physical restriction. However, the psychometric properties of these questions are unknown. Women classified as immobile scored significantly higher than women of the categories "intermediate" and "mobile" in the mean intensity of a series of experiences during the aggression (motor inhibition, trembling, closing the eyes, increased breathing, and cold) that are comparable to those observed in animals during tonic immobility. Nevertheless, there are no data about the psychometric properties of this second measurement either.

Heidt et al. (2005) and Fusé, Forsyth, Marx, Gallup, and Weaver (2007) were the first to investigate tonic immobility in humans with a validated questionnaire, the Tonic Immobility Scale (TIS) of Forsyth, Marx, Fusé, Heidt, and Gallup (2000), which assesses this phenomenon retrospectively and presents two subscales: physical immobility and fear. Specifically, they studied the occurrence of tonic immobility in women who had experienced childhood sexual abuse or sexual aggression/abuse, respectively. At least $41 \%$ of these women responded to these traumas with tonic immobility. In the first study, it was also verified that the probability of experiencing tonic immobility and the degree of physical immobility, but not of fear, were higher when the childhood sexual abuse involved the attempt or the act of vaginal coitus.

Up till the present, the possible occurrence of tonic immobility in traumas other than sexual traumas, or whether there are differences depending on different types of traumas has not been investigated with adequate measurements. Therefore, we wished to study whether there were differences in tonic immobility as a function of the worst trauma experienced, that is, the most traumatic event according to the each person's subjective appraisal. We proposed the hypothesis that tonic immobility would be higher in directly experienced traumas than in traumas subsequent to the observation or transmission of information. To all purposes, it is plausible to suppose that in the former case, fear and physical restriction (or the perceived incapacity of escaping) are higher. We did not formulate any hypothesis about the possible differences in tonic immobility among the diverse types of directly experienced traumas because there are no theoretical formulations or empirical data about this. The second hypothesis that we proposed was that tonic immobility would be higher in people who had experienced traumas than in people who had not (in the latter case, considering tonic immobility during their worst stressing experience). Likewise, and in accordance with the results of Vrana and Lauterbach (1994), we anticipated that the current posttraumatic symptomatology would be higher in the first group than in the second.

\section{Method}

\section{Participants}

The participants were university students from the third course of psychology of the University of Barcelona. We handed out 303 questionnaire booklets for the students to complete at home, given the nature of the topic. In total, 104 people (34\%) returned the booklet, although 4 were eliminated because they did not respond to the Traumatic Events Questionnaire. Mean age was 23.1 years $(S D=5.2)$. Of the sample, $87 \%$ were female and $88 \%$ were single.

\section{Measures}

Traumatic Events Questionnaire, modified from the Traumatic Events Questionnaire (TEQ) of Vrana and Lauterbach (1994). The original questionnaire assesses experiences with 11 specific types of trauma. For each trauma experienced, participants indicate the number of times it occurred, their age at that time, and, on a 7-point scale ranging from 1 (not at all) to 7 (extremely), whether they were injured, whether they perceived the situation as life threatening, how traumatic the event was at the time, and how traumatic it is now. Some items also ask for a description of the trauma. If individuals indicated more than 
one trauma, they should indicate which was the most traumatic event (the worst trauma). If they did not indicate any trauma, they should describe the worst stressful experience they had had and respond about it the same way as for the remaining items.

The modifications of the original questionnaire consisted basically of increasing the types of trauma from 11 to 15 . Specifically: (a) we separated suffering and witnessing serious accidents; (b) we extended car accidents to include travel accidents, we separated them from the rest of the accidents and we distinguished between experiencing and witnessing them; (c) we removed rape from the category of assault or physical aggression because of its different connotations and we included it within the category of unwanted sexual experiences that involve threat or the use of force; and (d) we separated childhood physical abuse and sexual abuse. The 15 types of trauma were: (a) suffering a serious industrial or agricultural accident, or a great fire or explosion; (b) witnessing a serious industrial or agricultural accident, or a great fire or explosion; (c) suffering a serious travel accident; (d) witnessing a serious travel accident; (e) suffering a natural catastrophe; (f) suffering assault or physical aggression; (g) suffering childhood physical abuse; (h) suffering childhood sexual abuse; (i) suffering physical or other abuse as an adult; (j) suffering sexual experiences by force or with threats; (k) having witnessed someone being mutilated, severely injured, or suffering violent death; (1) having been in serious danger of losing one's life or being seriously injured; $(\mathrm{m})$ receiving news of the mutilation, severe injury, or violent or sudden death of a loved one; (n) suffering any other very traumatic event; and (o) having had a traumatic experience that cannot be disclosed.

The Purdue Posttraumatic Stress Disorder Scale-Revised (PPTSD-R; Lauterbach \& Vrana, 1996). This scale assesses, on a 5-point rating scale, the frequency during the last month of the 17 symptoms of posttraumatic stress disorder (PTSD) corresponding to criteria B, C, and D of the Diagnostic and Statistical Manual of Mental Disorders, $4^{\text {th }}$ edition, Text Revision (American Psychiatric Association, 2000). Although it has three subscales (re-experiencing, avoidance, and arousal), we only used the total score. Responses on this scale referred to the worst trauma experienced or, in the case of people who stated they had not suffered any trauma, their worst stressful experience.

The Tonic Immobility Scale (TIS; Forsyth et al., 2000). This scale assesses the degree to which a person experiences various aspects of the tonic immobility response during the most recent sexual assault. Although the scale has two parts, only the first part has been analyzed psychometrically. This first part has 12 items that are rated from 0 to 6 , depending on the degree to which the participant experienced the aspects assessed (i.e., paralysis, trembling, incapacity to scream, numbness, sensation of cold, fear, feeling disconnected from oneself and the surroundings). Ten of these items assess the extension of tonic immobility during the trauma, whereas the other two involve feelings of guilt and the recall of the trauma. The first ten items are distributed in two factors: physical immobility and fear, with 7 and 3 items, respectively. The instructions and the first two items of the TIS were modified so that instead of referring to the most recent sexual assault, they referred to the worst trauma experienced or, in the case of people who had not suffered any trauma, the worst stressful experience.

Definition of a traumatic event. We considered that a traumatic event had occurred, from among the 15 listed in the modified TEQ, if the person responded affirmatively to the item and considered it traumatic (4 or higher on a 7point scale) at that time or currently; thus, we took into account the subjective impact of the trauma. The traumas classified by the participant as "Serious danger of losing my life or of being severely injured" or as "Another very traumatic event," but which, according to the description, corresponded to other kinds of traumas (specifically, a serious traffic accident, physical aggression and abuse) were counted as these kinds of traumas.

\section{Procedure}

The questionnaires were handed out in class but responded individually outside of class and returned in the next class. We explained to the students that we were performing a study about events that occur over one's lifetime, some of which could be traumatic, and about people's reactions to them. The students did not receive credits or any kind of compensation for participating in the investigation. The questionnaires were administered in the following order: TEQ, PPTSD-R, and TIS.

\section{Statistical Analyses}

The assumption of normality was met for the subscale of physical immobility, but not in the PPTSD-R. Therefore, we applied parametric tests (analysis of variance and Student's $t$ ) in the first case and nonparametric tests (Kruskal-Wallis and Mann-Whitney's $U$ ) in the second. When $p<.05$ (bilateral or two-tailed), the result was considered statistically significant.

\section{Results}

Internal consistency (Cronbach's alpha) was .926 for the PPTSD-R and .653 and .427 , respectively, for the subscales of physical immobility and fear of the TIS. As the reliability of the latter subscale was considered very low, we decided to use only the subscale of physical immobility.

Of the 100 participants, $70 \%$ had experienced some traumatic event. Table 1 presents the scores in the PPTSD-R and in physical immobility both of the people who had and who had not experienced traumas. The two groups differed 
significantly in: (a) the symptoms of posttraumatic stress experienced during the previous month (referring to their worst stressful experience in the case of those who had not suffered traumas); and (b) in physical immobility during the traumatic event (or during their worst stressful experience). According to Cohen's (1988) criteria, the effect sizes were moderate.

To determine whether there were differences in physical immobility as a function of the worst experienced trauma, these traumas were grouped into five categories to increase the sample size of the groups: (a) suffering a serious travel accident; (b) being the victim of an assault or physical aggression; (c) suffering physical/psychological or sexual abuse; (d) receiving news of the mutilation, serious injury or violent or sudden death of a loved one; and (e) other traumas (see Note "a" of Table 2 for a description of these other traumas). Table 2 displays the means and standard deviations of physical immobility of each of these five groups. According to the analysis of variance, there were no significant differences among them: $F(4,65)=1.485, p$ $=.217, r=.29$.

To test our initial hypothesis, we used the $t$-test to compare the group of news about mutilation/injury/death with each of the three groups in which the trauma had been directly experienced: serious travel accident, assault or physical aggression and physical/psychological or sexual abuse. The only significant difference was between the group of bad news about a loved one and that of physical/psychological or sexual abuse, $t(31)=2,643, p=.013, r=.43$. This effect size was moderate; the effect sizes of the comparisons with a serious travel accident and assault or physical aggression were $r=.18$ and $r=.34$, respectively. The group of physical/psychological or sexual abuse scored the highest of all. When comparing the the other three groups with this group, no significant difference was found, except the abovementioned one with the group of bad news about the mutilation/injury/death of a loved one. In the other two comparisons, the effect size was low, $r<.22$.

\section{Discussion}

The results obtained support the hypothesis that states that physical immobility is higher during a trauma than during the worst stressful experience in the case of people who did not suffer any traumas. However, physical immobility, as measured by the TIS, did not discriminate between diverse types of traumas, except that the score was lower in traumas consisting of receiving traumatic news than in traumas of physical/psychological abuse or sexual abuse. This only partially supports the other hypothesis proposed, as no differences in physical immobility were found between other directly experienced traumas (serious travel accident, assault or physical aggression) and receiving traumatic news. However, the absence of differences between the group with serious travel accident traumas and the group that had received traumatic news could be due to the lack

Table 1

Means and Standard Deviations of the PPTSD-R and Physical Immobility for People with and without Traumatic Experiences

\begin{tabular}{lccccccc}
\hline & \multicolumn{2}{c}{ Trauma $n=70^{\mathrm{a}}$} & \multicolumn{2}{c}{ No trauma $n=25^{\mathrm{b}}$} & Statistical test $^{\mathrm{c}}$ & $p$ & Effect size $(r)$ \\
& $M$ & $S D$ & $M$ & $S D$ & & \\
\hline PPTSD-R & 30.10 & 12.78 & 21.08 & 6.47 & $z=3.585$ & .0003 & .37 \\
Physical immobility & 17.09 & 7.27 & 10.60 & 7.08 & $t=3.855$ & .0002 & .37 \\
\hline
\end{tabular}

Note. PPTSD-R = Purdue Posttraumatic Stress Disorder Scale-Revised.

${ }^{\mathrm{a}} n=68$ in the case of the PPTSD-R. ${ }^{\mathrm{b}}$ Of the 30 people who did not report traumas, 5 did not complete the items about posttraumatic stress and physical immobility. 'Mann-Whitney's $z$ for the PPTSD-R (the assumption of normality was not met) and $t$-test for physical immobility.

Table 2

Means and Standard Deviations of Physical Immobility as a function of the Worst Trauma

\begin{tabular}{|c|c|c|c|c|c|c|c|c|c|c|c|}
\hline \multicolumn{10}{|c|}{ Types of Trauma } & \multirow{3}{*}{$p$} & \multirow{3}{*}{ Effect size $(r)$} \\
\hline \multicolumn{2}{|c|}{$\begin{array}{l}\text { Serious travel } \\
\text { accident } \\
n=10\end{array}$} & \multicolumn{2}{|c|}{$\begin{array}{c}\text { Assault or } \\
\text { physical aggression } \\
n=9\end{array}$} & \multicolumn{2}{|c|}{$\begin{array}{c}\text { Physical/ } \\
\text { psychological or } \\
\text { sexual abuse } n=13\end{array}$} & \multicolumn{2}{|c|}{$\begin{array}{l}\text { News about mutilation, } \\
\text { serious injury or death } \\
\text { of loved one } n=20\end{array}$} & \multicolumn{2}{|c|}{$\begin{array}{c}\text { Other } \\
\text { traumas }^{\mathrm{a}} \\
n=18\end{array}$} & & \\
\hline$M$ & $S D$ & $M$ & $S D$ & M & $S D$ & M & $S D$ & $M$ & $S D$ & & \\
\hline 19.30 & 8.37 & 16.89 & 8.40 & 20.00 & 6.47 & 14.40 & 5.60 & 16.83 & 7.85 & .217 & .29 \\
\hline
\end{tabular}

Note. ${ }^{\text {a }}$ This category included witnessing traumatic events $(n=7)$, serious danger of losing one's life $(n=3)$, death of loved ones $(n=3)$, serious disease of self or loved one $(n=2)$, and trauma that cannot be disclosed $(n=3)$. 
of statistical power, because the former group was small and the effect size was moderate.

Fusé et al. (2007) worked with 191 female university students who had suffered sexual abuse in childhood or sexual aggression, and they found that, with reference to these traumas, $41.7 \%$ of the sample scored 21 or higher in the subscale of physical immobility (significant immobility) and $10.4 \%$ scored 28 or higher (extreme immobility). In our case, considering the 36 people who had experienced their worst trauma directly (serious travel accident, assault or physical aggression, physical/psychological/sexual abuse, serious danger of losing their life, a potentially fatal disease), the two percentages were $44.4 \%$ and $11.1 \%$, respectively. These percentages are very similar to the former ones and suggest that tonic immobility may be typical not only of sexual traumas but also of other types of directly experienced traumas. This possibility was acknowledged by Fusé et al.

In addition to this, there are testimonies that a significant minority of people are paralyzed, placing their lives at risk, in catastrophes such as the sinking or explosion of oil platforms, shipwrecks and fires, or airplane emergencies (Leach, 2004). Likewise, Marks (1987) reports that a state of paralysis has been described in survivors of attacks by wild animals and in soldiers under machine-gun fire. In any case, in our study, the group with physical/psychological abuse $(n=10)$ or sexual abuse $(n=3)$ scored the highest in physical immobility, which, together with the lack of statistical power, advises the suitability of carrying out studies with larger samples in order to clarify whether physical immobility is more or less acute in these kinds of traumas.

Moreover, when appraising the absence of differences in physical immobility among most of the diverse types of trauma, it should not be forgotten that the type of trauma was based on the worst directly experienced trauma and that the worst traumas represent the upper extreme of the distribution of traumatic events (Breslau, 2001). It remains to be seen whether the absence of differences in physical immobility as a function of the type of trauma still appears when the type of trauma is based on a randomly selected trauma among those reported by each person.

On the other hand, we note that the internal consistency of the TIS subscale of fear was very low (.43), which prevented us from using the data of this subscale. In their second study, Fusé et al. (2007) found lower reliability (.65) for this subscale than for the subscale of physical immobility (.86). These data indicate that it may be necessary to elaborate more items for the subscale of fear. Another problem with this subscale is that, in contrast to that of physical immobility, it did not discriminate between women whose childhood sexual abuse involved the attempt or the act of vaginal coitus and women whose abuse did not involve this attempt (Heidt et al., 2005). It would also be interesting to investigate whether the existence of this fear factor is due to the fact that it is made up of the three TIS items whose response format is inverted. An interesting aspect is whether the questionnaire would still be bifactorial if these items were worded in the same direction as the rest of the items, or would it become unifactorial, as occurred when this was done with the Brief Fear of Negative Evaluation Scale (Carleton, McCreary, Norton, \& Asmundson, 2006). Irrespectively of the answer, more investigation of the psychometric properties of the TIS is needed.

This work presents several limitations. Firstly, it is a study with a low response percentage (34\%) and a relatively small sample; therefore, the conclusions should be taken as tentative and they require replication with larger samples. The low response percentage was probably facilitated by having allowed the participants to complete the questionnaires at home, by not offering incentives for participating, and because of the nature of the topic (some students commented that it was an emotionally tough topic). In any case, the percentage of people who reported having suffered some trauma in our study is similar to that of other works carried out with larger samples of university students (from 339 to $1,507)$ and high response percentages $(86 \%$ and $100 \%$ in the studies that report this datum). If, as in these studies, trauma is defined without taking into account its subjective impact, then the percentage of participants in our study who had experienced some traumatic event $(90 \%)$ is similar to that of other studies-67, 92, 84, and 94\%-(Bernat, Ronfeldt, Calhoun, \& Arias, 1998; Martín \& de Paúl, 2005; Vrana \& Lauterbach, 1994; Watson \& Haynes, 2007).

A second limitation is that the study was retrospective, with the memory biases that may be involved. Thus, tonic immobility may be remembered as more or less than it really was, so studies are necessary that assess its occurrence immediately afterwards or as soon as possible after the occurrence of the trauma. Lastly, the data were analyzed assuming that the traumas reported by the participants had really occurred. Naturally, it is possible that, in some cases, this is not true.

Despite its limitations, this is the first study that has investigated systematically the occurrence of tonic immobility in different types of trauma. In view of the lack of replications, the data obtained suggest that tonic immobility may occur with the same intensity in diverse types of directly experienced traumas.

\section{References}

American Psychiatric Association (2000). Diagnostic and statistical manual for mental disorders, DSM-IV-TR ( $4^{\text {th }}$ ed., revised text). Washington, DC: Author.

Bernat, J.A., Ronfeldt, H.M., Calhoun, K.S., \& Arias, I. (1998). Prevalence of traumatic events and peritraumatic predictors of posttraumatic stress symptoms in a nonclinical sample of college students. Journal of Traumatic Stress, 11, 645-664.

Bracha, H.S. (2004). Freeze, flight, fight, fright, faint: Adaptationist perspectives on the acute stress response spectrum. CNS Spectrums, 9, 679-685. 
Breslau, N. (2001). The epidemiology of posttraumatic stress disorder: What is the extent of the problem? Journal of Clinical Psychiatry, 62 (suppl. 17), 16-22.

Carleton, R.N., McCreary, D.R., Norton, P.J., \& Asmundson, G.J.G. (2006). Brief Fear of Negative Evaluation Scale-Revised. Depression \& Anxiety, 23, 297-303.

Cohen, J. (1988). Statistical power analysis for the behavioral sciences $\left(2^{\text {nd }}\right.$ ed.). Hillsdale, NJ: Erlbaum.

Forsyth, J.P., Marx, B., Fusé, T.M.K., Heidt, J., \& Gallup, G.G., Jr. (2000). The Tonic Immobility Scale. Albany, NY: Authors.

Fusé, T., Forsyth, J.P., Marx, B., Gallup, G.G., \& Weaver, S. (2007). Factor structure of the Tonic Immobility Scale in female sexual assault survivors: An exploratory and confirmatory factor analysis. Journal of Anxiety Disorders, 21, 265-283.

Galliano, G., Noble, L.M., Travis, L.A., \& Puechl, C. (1993). Victim reactions during rape/sexual assault: A preliminary study of the immobility response and its correlates. Journal of Interpersonal Violence, 8, 109-114.

Gray, J.A. (1987). The psychology of fear and stress ( $2^{\text {nd }}$ ed.). Cambridge: Cambridge University Press.

Heidt, J.M., Marx, B.P., \& Forsyth, J.P. (2005). Tonic immobility and childhood sexual abuse: A preliminary report evaluating the sequela of rape-induced paralysis. Behaviour Research and Therapy, 43, 1157-1171.

Lauterbach, D., \& Vrana, S. (1996). Three studies on the reliability and validity of a self-report measure of posttraumatic stress disorder. Assessment, 3, 17-25.
Leach, J. (2004). Why people 'freeze' in an emergency: Temporal and cognitive constraints on survival responses. Aviation, Space, and Environmental Medicine, 75, 539-542.

Marks, I.M. (1987). Fears, Phobias and Rituals: Panic, Anxiety, and their Disorders. Oxford: Oxford University Press. [Spanish translation: Miedos, fobias y rituales 1: Los mecanismos de la ansiedad. Barcelona: Martínez Roca, 1991].

Martín, J.L., \& de Paúl, J. (2005). Situaciones traumáticas: Un estudio sobre su prevalencia en población universitaria. Psicología Conductual, 13, 79-96.

Moskowitz, A. (2004). 'Scared Stiff': Catatonia as an evolutionarybased fear response. Psychological Review, 111, 984-1002.

Suarez, S.D., \& Gallup, G.G. (1979). Tonic immobility as a response to rape in humans: A theoretical note. Psychological Record, 29, 315-320.

Vrana, S., \& Lauterbach, D. (1994). Prevalence of traumatic events and post-traumatic psychological symptoms in a nonclinical sample of college students. Journal of Traumatic Stress, 7, 289-302.

Watson, S.B., \& Haynes, S.N. (2007). Brief screening for traumatic life events in female university health service patients. International Journal of Clinical and Health Psychology, 7, 261-282.

Received July 25, 2007

Revision received February 8, 2008 Accepted April 30, 2008 